\title{
Heat islands over Mumbai as revealed by autorecorded thermograph data
}

\author{
A K Srivastava, ${ }^{1, *}$ James Voogt $^{2}$, S R Kshirsagar ${ }^{1}$ and Kavita Srivastava ${ }^{3}$ \\ ${ }^{1}$ India Meteorological Department, Shivajinagar, Pune 411 005, India. \\ ${ }^{2}$ Department of Geography, University of Western Ontario, London ON N6A 5C2, Canada. \\ ${ }^{3}$ India Meteorological Department, New Delhi, India. \\ *Corresponding author. e-mail: aksrivastava@hotmail.com
}

This study examined hourly temperature data of two locations of Mumbai metropolitan city. One data point (Coloba, Mumbai) is in centre of the city and the other one (Santacruz, Mumbai) is at the airport. The study finds that there were many occasions when night-time hourly temperatures over the city centre were considerably higher than that of the airport, even though temperature at the time of sunset at both the places was nearly same. In this study, the occasions, when hourly night-time temperature over city was more than that of the airport by objectively defined threshold value $\left(3.0^{\circ} \mathrm{C}\right.$ in this study) for most of the hours in the night, were termed as heat island events. Analysis of the study reveals that these events are mostly confined to November-February months. The study also found that frequency of such events has doubled in recent two decades in comparison to the earlier two decades.

\section{Introduction}

The term 'heat island', according to Glossary of Meteorology (2009) refers to any area, populated or not, which is consistently hotter than the surrounding area. However, the term, 'heat island', is popularly used to define a region (having relatively maximum density of large number of tall buildings. concrete roads, etc.) of any big city, which is considerably warmer in the night than the other areas of the city. Large number of tall buildings (in comparison to the open areas) put some sort of hindrance for the outgoing long wave radiation to the sky and this is the basic cause of night-time warming. In addition, calm wind (usually more prevalent in winter season) inhibits the mixing of heat process to some extent and these all help in retaining more heat over the region. The phenomenon was first investigated and described by Luke Howard in the 1820s, although the phenomenon was not named as the heat island. Theoretically, urban heat island (UHI) may form in any time of the day during a year. However, during the day time, continuous heating creates the necessary convection for the mixing process and the heating is redistributed. Therefore, temperature difference during the day over the region of high density of buildings/urban structures and the relatively open areas is usually not very significant. During the nighttime, sun-induced convection is weak/negligible and therefore, large difference of temperature over the two regions, on some occasions, could be observed particularly, when winds are weak.

The main cause of the urban heat island is modification of the land surface by urban development, which uses materials that effectively retain heat and the emission of heat by human activities. Concrete and asphalt, the materials commonly used in urban areas for pavement and roofs, have significantly different thermal bulk properties (including heat capacity and thermal conductivity) and surface radiative properties (albedo and emissivity).

Keywords. Heat island; surface heat island model; thermograph. 
In addition, waste heat generated by energy usage by the in situ residents is also a prime contributor. Further, due to lack of vegetation, there is not much evapotranspiration (the process which lowers the temperature by absorbing the heat) in urban areas. As population centres grow, more and more buildings are erected and it results in more concretizations of land. These growing centres, obviously with more energy need, produce more waste heat and thus force corresponding increase in average temperature. These all lead to a change in the energy balance of the urban area, often leading to higher temperatures than the surrounding rural areas.

Some other causes of a UHI are due to geometric effects of the high rise multi-storied buildings. The tall buildings within many urban areas provide multiple surfaces for the reflection and absorption of sunlight, increasing the efficiency with which urban areas are heated. This is called the 'urban canyon effect'. Moreover, theses buildings block winds up to certain extent and ultimately inhibit cooling by convection. High levels of pollution in urban areas can also increase the UHI, as many forms of pollution change the radiative properties of the atmosphere.

Several studies in the metropolitan cities of developed nations have brought out this aspect and many have even suggested some measures to minimize its adverse impact. However there are very limited studies from the developing world as it requires sufficiently large network of micro level observatories (manual or automatic) reporting simultaneously. In India, there are few studies, viz., by Daniel and Krishnamurthy (1973) and Mukherjee and Daniel (1976) which reported heat island like phenomenon in Mumbai on few occasions. These studies analyzed meteorological data observed by portable meteorological instruments using a mobile vehicle in clear winter nights. Daniel and Krishnamurthy (1973) found that the heat island was located over some parts of the city with highest contrast between the urban and rural areas of $6.0^{\circ} \mathrm{C}$ during winter months of 1972 . Similarly, Mukherjee and Daniel (1976) observed that highest contrast of temperature between the urban and rural suburbs of Mumbai to be around $11^{\circ} \mathrm{C}$, in January 1976.

In this study, we have analyzed long series daily autographic temperature records of two locations [one at a city site (Colaba) and the other at the airport (Santacruz) representing relatively semiurban location] of Mumbai to examine existence of this sort of phenomenon. Mumbai is one of the largest metropolises of South Asia. The early development of Mumbai was mainly confined to the south. Slowly as Mumbai developed into an urban conglomerate, there was a rapid urban sprawl from the south to north in the last few decades. Most of this growth has been a result of conversion of agricultural land or reclamation of wet lands. Greater Mumbai may be categorized into Mumbai city and Mumbai suburban regions. 'Colaba' station under study (city site) is situated in the Mumbai city (extreme south) which had been a hub of development right from early days, while 'Santacruz' is situated in the north suburban area and therefore, it witnessed developmental activities (commercial, residential and industrial) much later than 'Colaba' region. Moreover, there is some restriction on high-rise buildings in the vicinity of Santacruz airport (being one of the biggest international airports). Further, suburban areas around Santacruz have more natural areas/open spaces, vacant lands and urban villages. In fact, area of vacant land in Santacruz area is 10 times more than that of in Colaba region. Similarly, area of urban villages in Santacruz region is more than $1 \frac{1}{2}$ times of that of Colaba region (Source, Greater Mumbai municipal corporation website: www.mcgm.gov.in/).

Although the exposure of meteorological stations of the city has not altered much over the years, highrise buildings and energy consumption in the city have significantly increased; while, around the airport still there is restriction on the construction of high rise and area around the airport are relatively more open. Therefore, temperature records of the airport may be considered as representative of the temperature of a semi-urban site.

Further, by applying a force restore model with rural background to simulate night-time hourly temperature at both the places, we found that the hourly temperature data of the airport during the night was closer to the simulated hourly temperature of the model. This also suggests that usual fall in the hourly temperature during the night at the airport follows some sort of the expected fall usually observed over the area with rural background. This indirectly suggests that it would not be incorrect to consider temperature data of the Mumbai airport 'Santacruz' as representative of the data of semi-urban/rural background station.

In this study, we examined all the cases (out of $41 \times 365$ days) wherein, hourly temperature of Mumbai city during night was more than that of Mumbai airport by an objectively defined threshold value for most of the hours. We found that frequency of such events when Mumbai city nocturnal temperature was appreciably higher than that of the airport, are generally on the rise. We further simulated night-time hourly temperature, using a simple surface heat island model (SHIM) with rural background and compared the relative fall of temperature at two locations with the modelled values. On many occasions, the temperature fall during the night, at the airport was similar to that of modelled values particularly for the late hours of night. 


\section{Data and analysis}

We used daily autographic temperature data from 1969-2009 for our analysis. Difference in hourly temperature data at both the places (city and airport) for all the 24 hours of each day of the data period was calculated. Occasions when temperature of both the stations around sunset (18:00 hrs local time in winter and 19:00 hrs in other seasons) did not differ much $\left(\leq 0.5^{\circ} \mathrm{C}\right)$ and when the difference in hourly temperatures after the sunset was substantially higher (greater than $3.0^{\circ} \mathrm{C}, 3.5^{\circ} \mathrm{C}$ and $4.0^{\circ} \mathrm{C}$ ) for most of the hours before the next day's sunrise were flagged. Selection of $3.0^{\circ} \mathrm{C}$ as the threshold difference value is based on the hourly climatological temperature difference between the two locations and its standard deviation. In this study, we defined 'heat island phenomenon', when following criteria were satisfied:

(1) At the sunset hour, temperature of Mumbai city was nearly the same as that of Mumbai airport and did not differ more than $0.5^{\circ} \mathrm{C}$.

(2) The hourly temperature value of Mumbai city (Colaba) was greater than that of Mumbai airport (Santacruz) for all the 12 night hours after the sunset.

(3) Hourly temperature value of Mumbai city was greater than that of Mumbai airport by more than the threshold value for most (at least for the half of 12 night hours, i.e., 6 hours) of the hours during night after the sunset.

After flagging those days, we analyzed decadal frequency of such events. We also examined linear trend in yearly frequency of the occasions when Mumbai city (Colaba) after the sunset hour was warmer than Mumbai airport by $3.0^{\circ}, 3.5^{\circ}$ and $4.0^{\circ} \mathrm{C}$ respectively, for most of the 12 night hours. We further used the SHIM with rural background to simulate night-time temperature on a few days.

\section{Surface heat island model (SHIM)}

The SHIM is a simple force-restore model that simulates the nocturnal cooling of an urban canyon (walls and street) under 'ideal' conditions of calm winds and clear skies. SHIM is initiated at the time of sunset and requires several inputs to run the model. These include initial surface temperatures, emissivity, thermal admittance, and deep temperatures for each canyon facet, incident long wave radiation $(L \downarrow)$ at the top of the canyon and the canyon height to width ratio $(\mathrm{H} / \mathrm{W})$. The model is set up to calculate surface cooling for each of the canyon facets and also calculates the surface radiation budget $\left(L^{*}\right)$ for each of the facets. More details are given in Johnson et al. (1991).

The force-restore equation used by SHIM for the nocturnal cooling of a homogeneous substrate with layer thickness $D$ is given as:

$$
\frac{d T\left(D_{i}, t\right)}{d t}=\frac{\sqrt{2 \Omega}}{\mu_{t}} L_{t}^{*}-\Omega\left(T_{t}\left(D_{i}, t\right)-T_{D}\right)
$$

where $T\left(D_{i}, t\right)$ is the temperature of a layer $I$ at time $t, T_{D}$ represents a 'deep temperature usually taken as average temperature of the last 3 days' that is constant, $\mu$ is the thermal admittance of the soil, $\Omega$ is the angular frequency of the heating wave and $L^{*}$ is the net long wave radiation.

The applicability of the SHIM is restricted due to limitations of the model in its current form. A major limitation of the SHIM is that the model can only be applied when the weather conditions are stationary.

For the rural background, model becomes simple and is given below

$$
\begin{aligned}
\frac{d T_{r}}{d t}= & \frac{2}{c} L_{r}^{*}-\Omega\left(T_{r}-T d_{r}\right)=\frac{2 \varepsilon}{c} L \downarrow \\
& -\left(\frac{2 \varepsilon \sigma}{c} T_{r}^{4}\right)-\Omega\left(T_{r}-T d_{r}\right)
\end{aligned}
$$

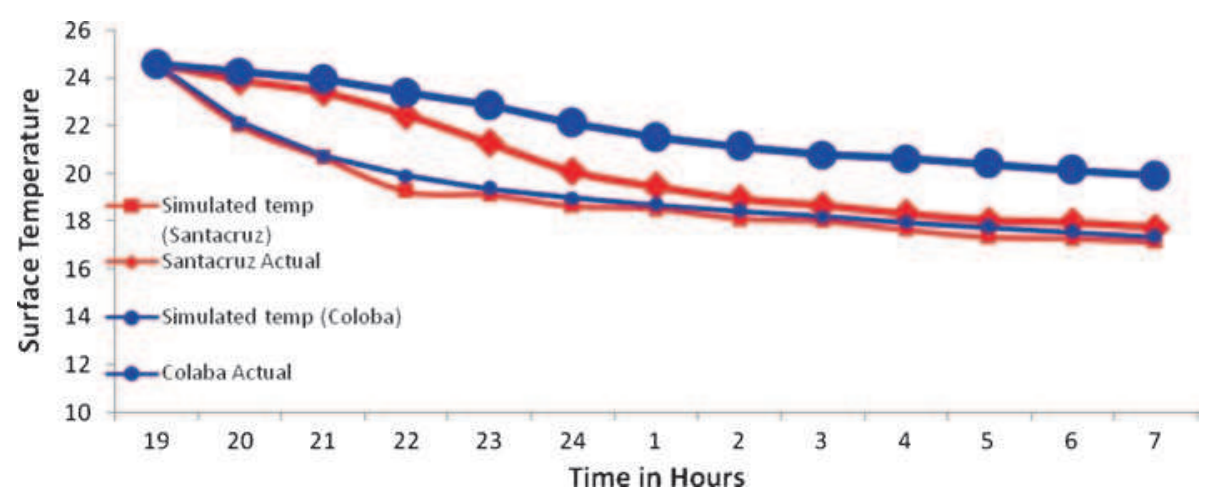

Figure 1. Climatology of hourly-simulated temperature (averaged for 31 days) values using force restore model vis-a-vis actual hourly temperature (averaged for 31 days) for Mumbai city (Colaba) and Mumbai airport (Santacruz) during January 1995. 
where $\varepsilon$ is the atmospheric emissivity (ability of the atmosphere to emit long wave radiation). This emissivity is a function of both temperature and humidity.

It can be calculated (Idso 1981) as:

$$
\varepsilon=0.7+5.95 \times 10^{-5} e_{a} \exp \left(1500 / T_{\text {air }}\right)
$$

where $e_{a}$ is the vapour pressure of the air (mb) calculated from $T_{\text {air }}$ and $\mathrm{RH}$ or dew point temperature information.

$T_{\text {air }}$ is screen level air temperature (Kelvin) $L \downarrow=e_{a} \varepsilon T_{\text {air }}^{4}$

$T_{\mathrm{r}}=T_{\text {air }}=$ Screen level air temperature

$\square$ Hrly temp difference (City-Airport) climatology

$\square$ Standard deviation of the hrly difference in temp

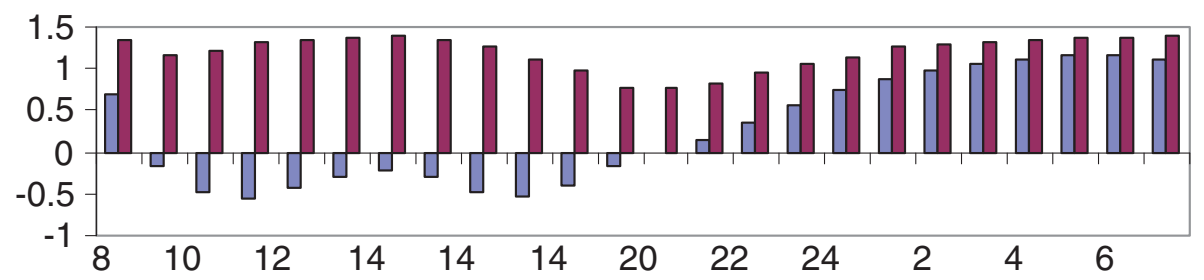

(a)

Hours (local time)

Diurnal range

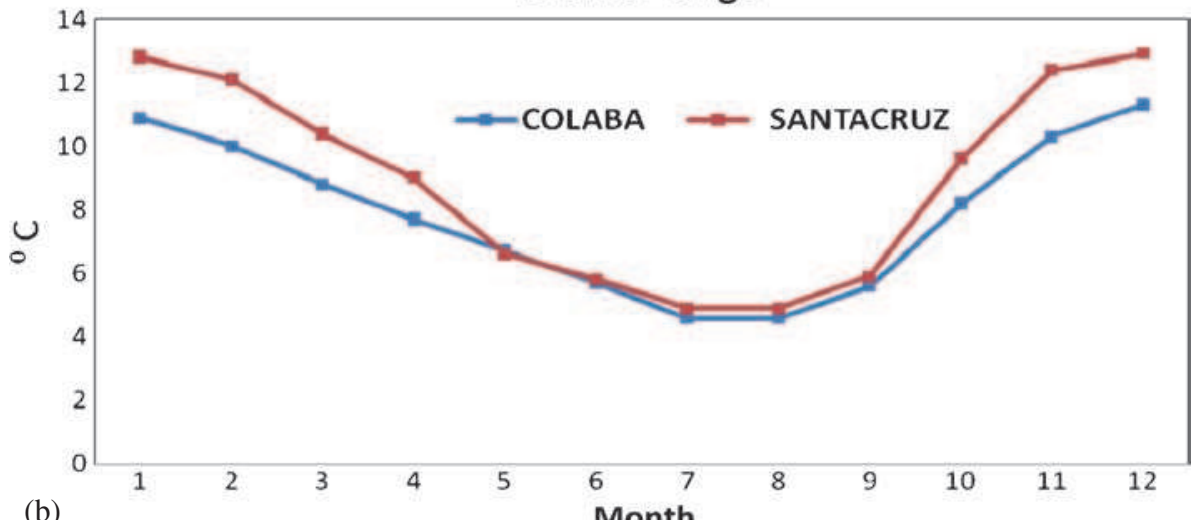

Figure 2. (a) Climatology of hourly difference in temperature and its standard deviation. (b) Climatology of diurnal range in temperature during different months.

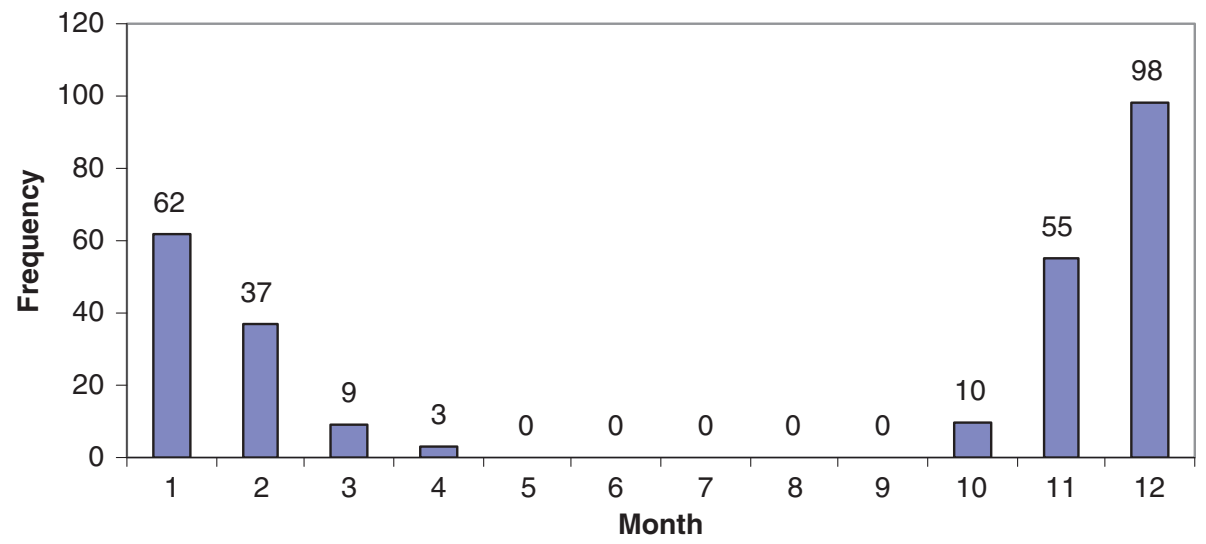

Figure 3. Monthwise (total) number of occasions, when hourly temperature at Mumbai city in a particular night, was more than $3.0^{\circ} \mathrm{C}$ than that of Mumbai airport, for at least six (out of 12) hours after the sunset for period 1969-2009. On all such occasions, difference of temperature at the sunset hour was within $0.5^{\circ} \mathrm{C}$. 


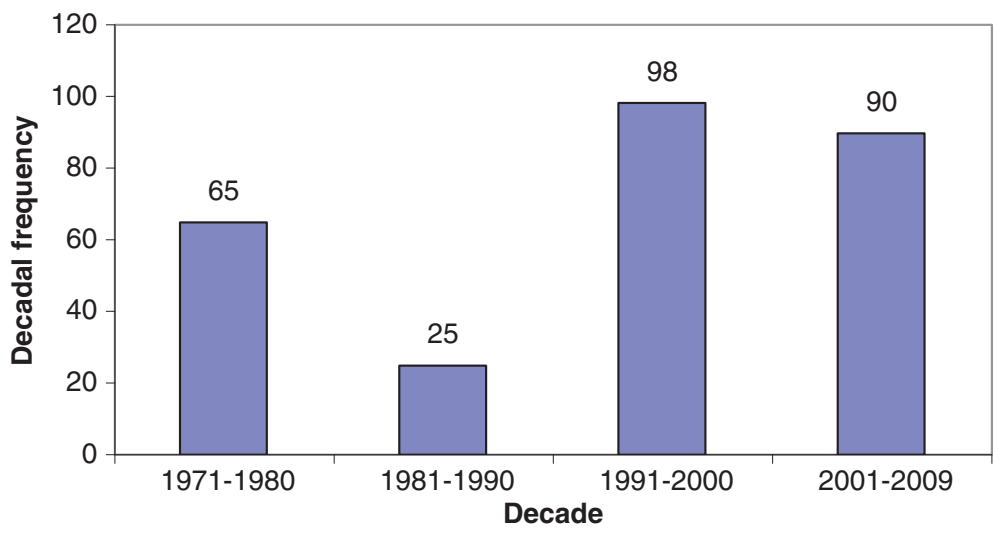

Figure 4. Decadal frequency of occasions when difference between hourly temperature of Mumbai city and airport, was more than $3.0^{\circ} \mathrm{C}$ for most of the hours after the sunset.

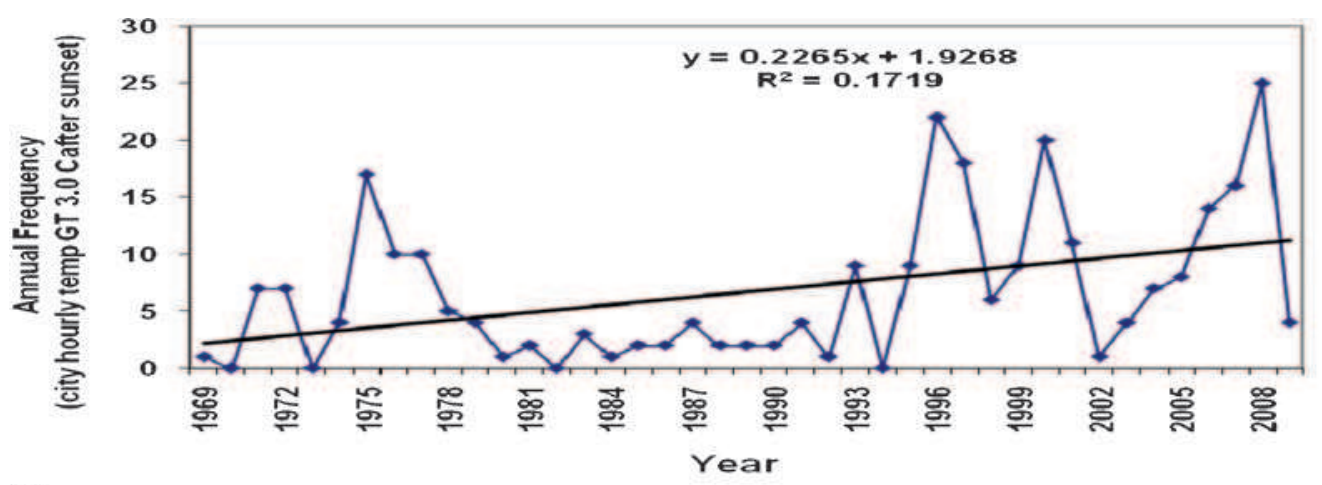

(a)

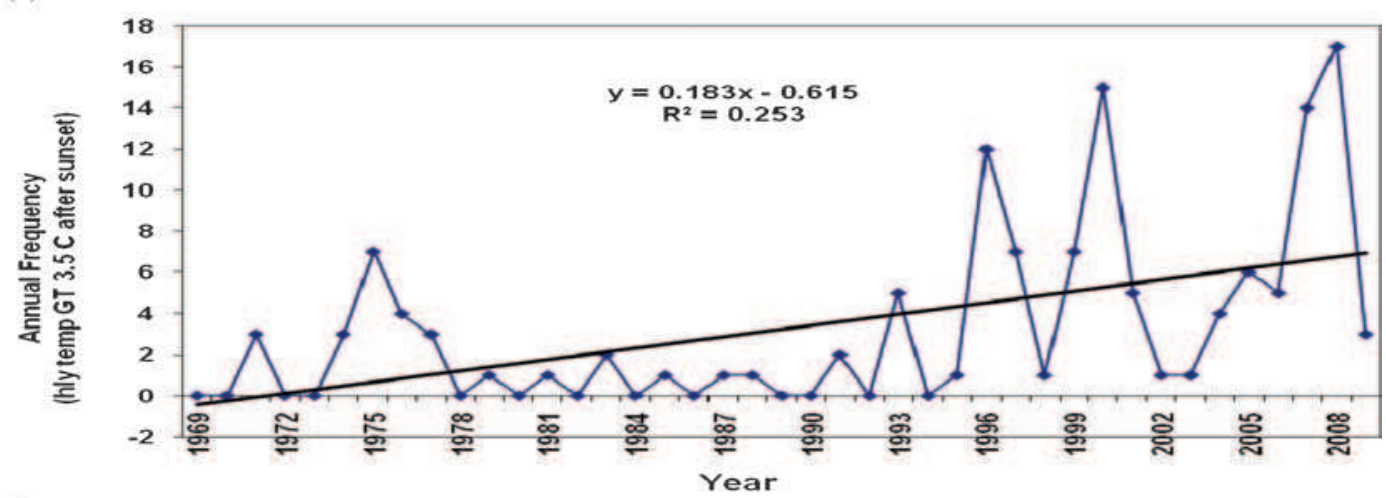

(b)

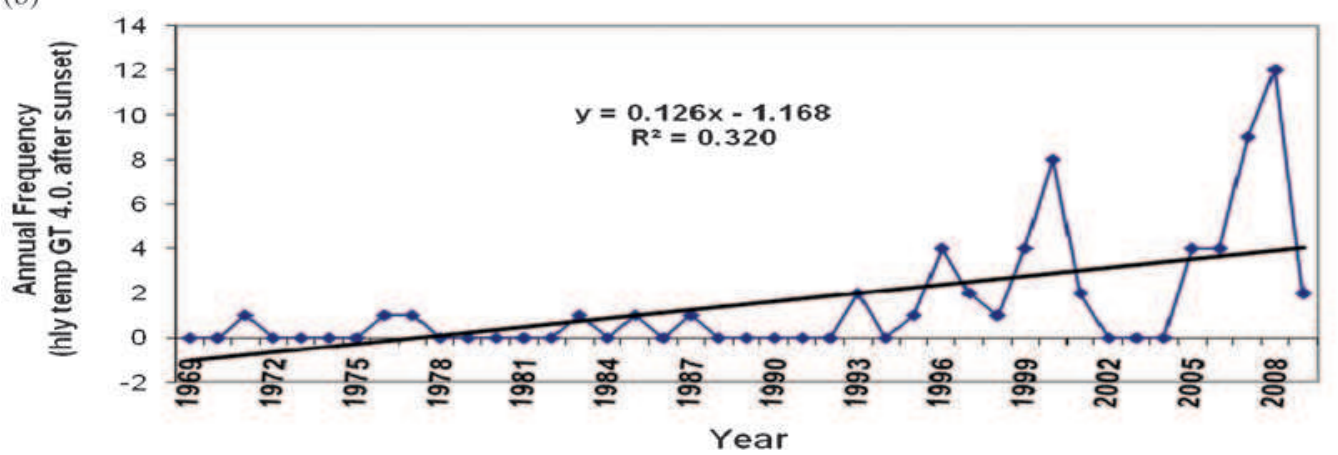

(c)

Figure 5. Linear trend in the frequency of number of occasions when difference between hourly temperature of Mumbai city and airport, was more than. (a) $3.0^{\circ} \mathrm{C}$, (b) $3.5^{\circ} \mathrm{C}$ and (c) $4.0^{\circ} \mathrm{C}$, for most of the night hours. 
$T d_{r}=$ Deep temperature, taken average of past 3 days air temperature

$$
c=\mu \sqrt{\frac{2}{\Omega}}
$$

$\mathrm{VFt}+\mathrm{VFs}=1.0$, is sky view factor

Ldown $=$ Ldsky ${ }^{*}$ VFs + Ldterr*VFt.

In case of rural simulation, VFs $=1.0$ and VFt $=0$.

25 Jan 1977

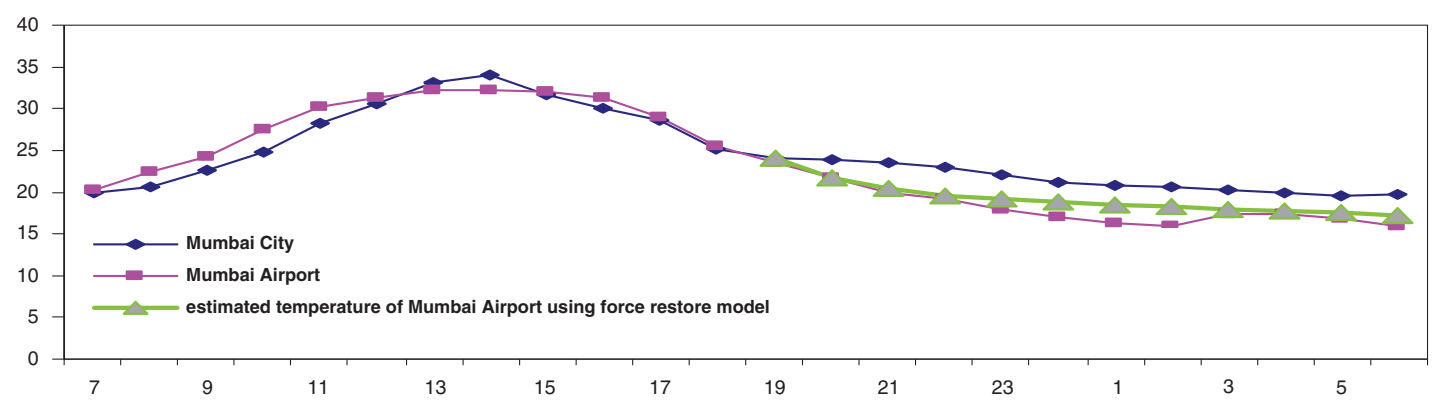

(a)

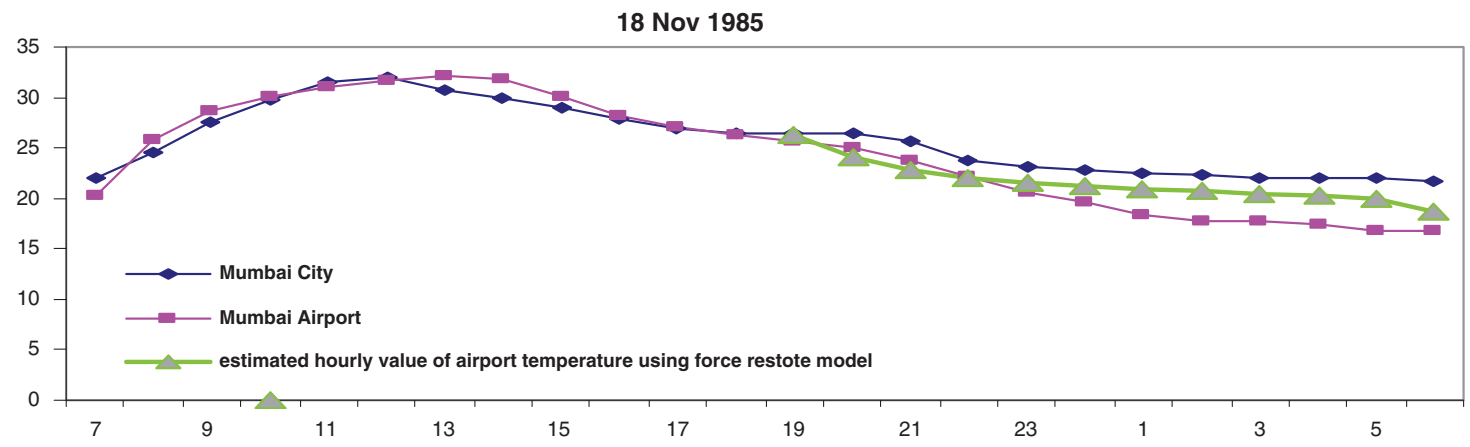

(b)

9 April 1996

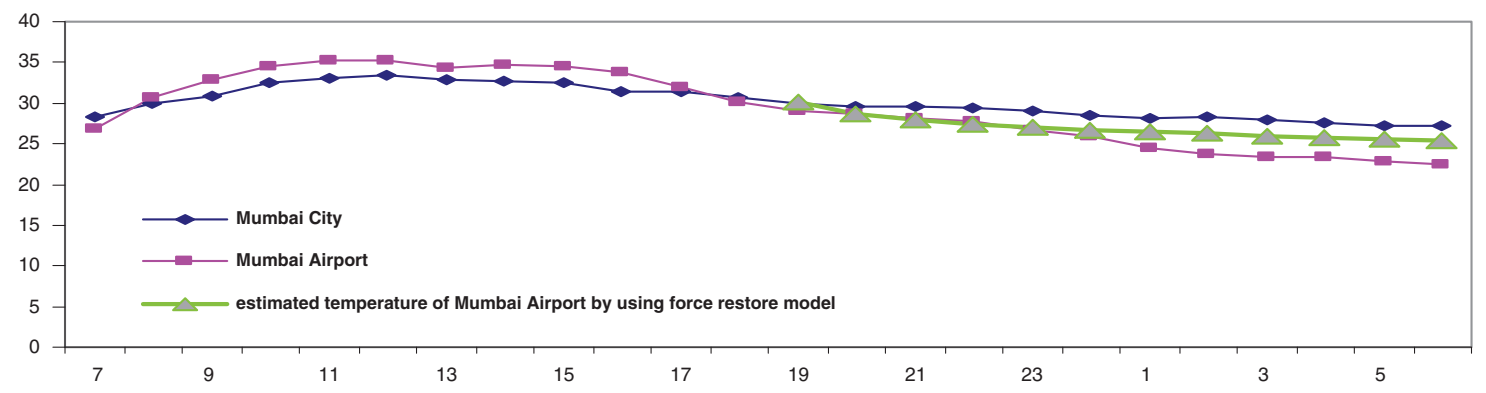

(c)

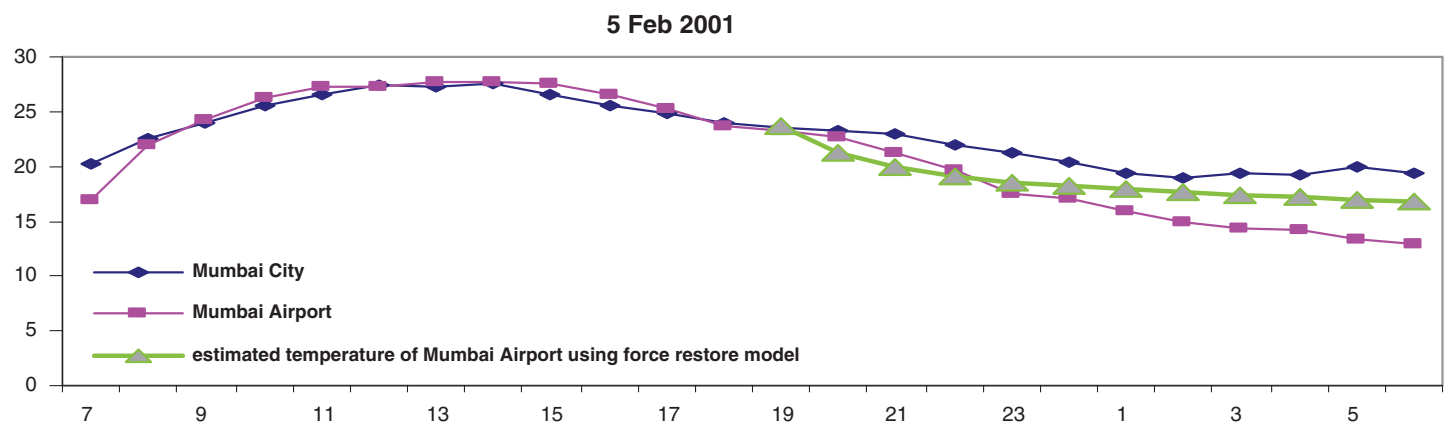

(d)

Figure 6. Hourly temperature (24) pattern on four occasions (1) 25 January 1977, (2) 18 November 1985, (3) 9 April 1996, and (4) 5 February 2001, when difference in hourly temperature over Mumbai city after sunset was more than $4.0^{\circ} \mathrm{C}$ from that of Mumbai airport. Simulated hourly temperature using the force restore model of the Mumbai airport after the sunset is also plotted. 


\section{Results and discussions}

We applied a force restore model with rural background to simulate night-time hourly temperature over both the places for each 31 days of January of a randomly selected year 1985 . We averaged simulated hourly values for each hour over the days (31) of the month and compared with the actual hourly temperature (averaged for 31 days) values. We found that temperature data of the airport were closer to the simulated temperature of the model (figure 1). We repeated this exercise for two other randomly selected years to verify the results. This indirectly suggests that data of the airport may be taken as representative of rural/semi-urban background station data.

Figure 2(a) shows the climatology of differences in hourly temperature and its standard deviation of the whole data period. For this study, we rearranged hourly temperature data in such a way that hourly temperature of 24 hours of a day consists of temperature records from around sunrise hour of a day to the hour before the next day's sunrise. Thus, in the rearranged format, hourly temperature data for 24 hours of a particular day consists of hourly temperature data from 7:00 to 24:00 of the same day and 1:00 to 6:00 hour of the next day. We observed that difference in hourly temperature (Mumbai city-Mumbai airport) during most of the daytime hours was slightly negative and the same for the night hours was substantially positive. This suggests that during the daytime, city temperature is slightly lower than that of the airport while it is just opposite for night-time. This is a peculiar characteristic of stations with the urban and semi-urban/rural backgrounds. This again justifies selection of Mumbai city and Mumbai airport as representative of urban and semi-urban/rural background stations. It may be mentioned that large concentration of high-rise buildings in high density urbanized parts of a city partially obstruct (in comparison to the relatively semi-urban/rural areas) the short wave radiation coming from the sun during the day and the same structure obstruct the outgoing long wave radiation to the sky during the night. This invariably results in relatively slightly lower day temperature and slightly higher night temperature over the most urbanized sector than those of the nearby semi-urban/rural parts. We may further see that standard deviation (SD) for most of the hourly temperatures are around one. Only, for a few late night hours just before the sunrise (in rearranged hourly data format), the $\mathrm{SD}$ is around 1.5. Based on this climatology, we selected a threshold value of $30^{\circ}$ (which is even higher than the mean difference in temperature + maximum SD) as the difference (Mumbai cityMumbai airport) in night-time (after the sunset hour to the next day sunrise hour) hourly temperatures of the two places for most of the night hours, to define heat island like situation.

Figure 2(b) shows average diurnal range of temperature for the two places for all the 12 months. We observed that diurnal range over the Mumbai airport was higher than that of Mumbai city during most of the months except months of the monsoon season by around $1.0^{\circ}-2.0^{\circ} \mathrm{C}$.

Figure 3 shows the monthwise frequency of occasions when Mumbai city according to the classification adopted in the study was significantly warmer in the night than the airport for the dataset of the study, viz., 1969-2009. It may be seen that occurrence of such events is maximum (98) in December, followed by January (62) and November $(55)$. These months are characterized by clear sky and light wind conditions, ideally suited for

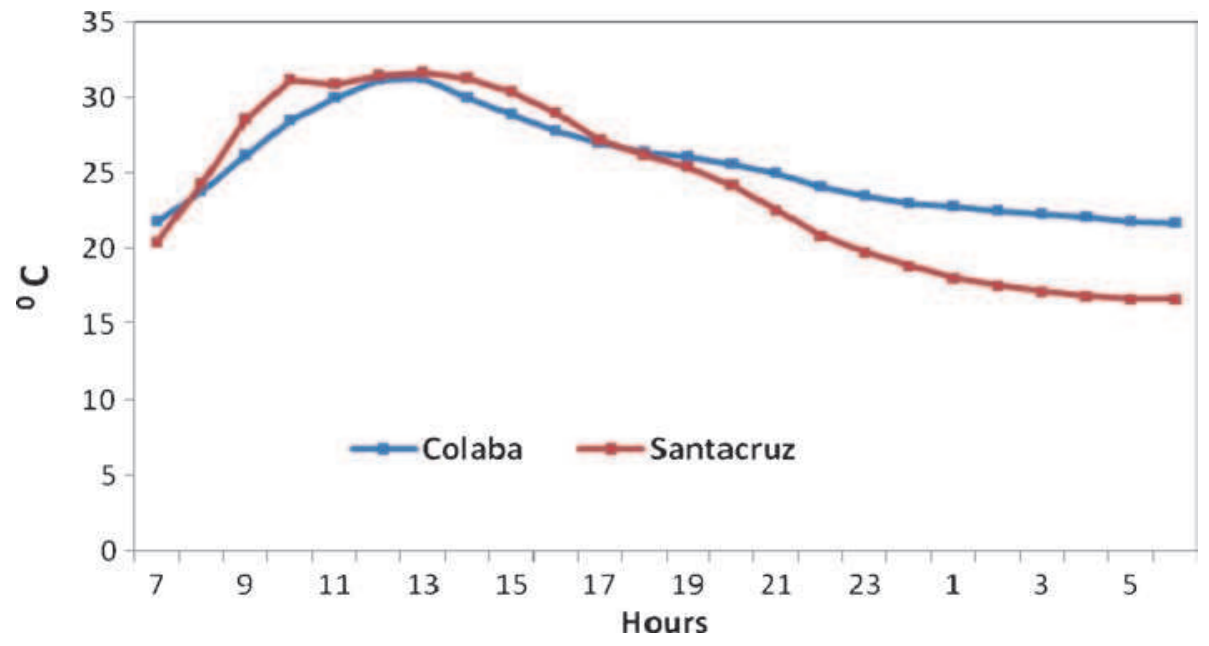

Figure 7. Composite diagram of 24 temperature patterns for all the occasions (total 42), when during night-time hourly temperature of Mumbai city was $4.0^{\circ} \mathrm{C}$ higher than that of Mumbai airport for most of the hours. 
occurrence of heat island phenomenon. There are relatively fewer occasions of this phenomenon in March (transition period from winter to summer). From May to September, we could not find even a single occasion satisfying the criteria selected in our study. It is worth mentioning that most of the months from May to October are dominated by strong monsoon winds, cloudy skies and significant weather like frequent high rainfall events, which may be detrimental for heat island formation.

Similarly, decadal frequency of these events for four decades, 1971-1980, 1981-1990, 1990-2000 and 2001-2009 is shown in figure 4. In the last two decades, frequency of this event is much higher and total frequency of events in the last two decades (19 years) is more than twice than that for the first two decades (20 years).

We also examined the trend in the annual frequency of such events, i.e., when hourly temperature of Mumbai city during night-time was considerably higher than that of Mumbai airport. The linear trend in the frequency of number of occasions when difference in hourly temperatures after sunset was higher than $3.0^{\circ}, 3.5^{\circ}$ and $4.0^{\circ} \mathrm{C}$ for most of the night hours is shown in figure 5 . We find an increasing trend in all the three cases and this trend is statistically significant at $1 \%$ level (99\% confidence), suggesting that these events are rising very rapidly. It may be seen that annual frequency of such events was less than 5 from the year 1981 up to 1993, with slight negative trend. Subsequently, there is significant rise in the frequency of these events. Although, this study has not examined any specific cause for the rise of such events; relatively rapid urbanization around the city may be one of the probable causes.

Figure 6 shows temperature pattern (24) over the two locations for four selected days (one in each decade), when night-time Mumbai city temperature was $4.0^{\circ} \mathrm{C}$ higher than that of airport temperature for most of hours. In figure 6(a), hourly temperature of the two stations on 25th January, 1977 is shown. We observed that hourly temperature of the airport was higher than that of the city in daytime while the city temperature is considerably higher than that of the airport temperature during night-time and the difference in the night temperature is more than $4.0^{\circ} \mathrm{C}$ after late night and early morning of the next day. Similar feature could also be seen in figure $6(\mathrm{~b}, \mathrm{c}$ and $\mathrm{d})$ and on these occasions, again, Mumbai city was appreciably warmer than the airport in the night. These situations as per criteria selected in this study, have been classified as heat island phenomenon for Mumbai city. Composite diagram of 24 temperature patterns for all occasions (total 42) when during night-time hourly temperature of Mumbai city was $4.0^{\circ} \mathrm{C}$ higher than that of Mumbai airport for most of hours is shown in figure 7 .

We have further used the SHIM model with rural background to estimate the night temperature at Mumbai airport for the dates on which heat island phenomenon were shown and those results are also shown in figure 6 . It may be seen that the temperature fall over airport was sharper than the modelled values. This shows that the model underestimated the rural cooling.

\section{Conclusions}

The study analyzed hourly data of two locations of Mumbai metropolitan city. One data point is in centre of the city and the other one is at the airport where open spaces/vacant lands are considerably more, while high-rise buildings are also restricted at the airport. Heat island phenomenon over city was defined when difference of hourly temperature over the city was $3.0^{\circ} \mathrm{C}$ higher than that of the airport temperature for most of the hourly temperatures, after the sunset to the next day sunrise. Selection of the threshold difference value of $3.0^{\circ} \mathrm{C}$ was based on climate mean difference in temperature and its standard deviation. Heat island events (defined in the above manner) were mostly confined to November-February months, when sky is generally clear and winds are calm. The study also highlights that frequency of such events has doubled in recent two decades in comparison to the previous two decades. The SHIM model was used to simulate night-time temperature at the airport on such days to find that the model underestimated semi-urban/rural cooling.

\section{Acknowledgements}

Authors are grateful to the DGM, IMD for providing necessary facilities for the study. They are thankful to Shri B Mukhopadhyay, LACD $\operatorname{ADGM}(\mathrm{R})$ for providing constant encouragement. Thanks are also due to Smt. U J D'souza for the preparation of the manuscript.

\section{References}

Daniel C E J and Krishnamurthy K 1973 Urban temperature fields at Poona and Bombay; Indian J. Met. Geophys. 24(4) 407-412.

Glossary of Meteorology 2009 Urban Heat Island; American Meteorological Society.

Idso S B 1981 A set of equations for full spectrum and 8 to $14 \mathrm{~mm}$ and 10.5 to $12.5 \mathrm{~mm}$ thermal radiation from cloudless skies; Water Resour. Res. 17(2) 295-304.

Johnson G T, Oke T R, Lyon T J, Steyn D G, Watson I D and Voogt J A 1991 Simulation of surface urban heat 
islands under 'ideal' conditions at night, Part 1: Theory and tests against field data; Bound. Layer Meteorol. 56 275-294.

Luke Howard 1820 The climate of London: Deduced from Meteorological observations made at different places in the neighbourhood of the metropolis; 2 vols.

Mukherjee A K and Daniel C E J 1976 Temperature distribution over Bombay during cold night; Indian J. Met. Geophys. 27(1) 37-41.

MS received 24 September 2014; revised 31 August 2015; accepted 31 August 2015 